\section{Undergraduate experience and self-assessed confidence in paediatric dentistry: comparison of three UK dental schools}

\author{
H. D. Rodd, ${ }^{1}$ M. Farman, ${ }^{2}$ S. Albadri ${ }^{3}$ and I. C. Mackie ${ }^{4}$
}

IN BRIEF

- Outlines what paediatric dentistry experience UK dental students receive.

- Enables an appreciation of which areas students feel least and most confident in, in relation to treating children.

- Elicits recognition that trauma-related teaching needs to be enhanced within the undergraduate curriculum.

- Gives evidence for how outreach teaching contributes to increased undergraduate clinical exposure in key skills.

Previous studies have suggested that dental students may not receive sufficient clinical experience in core paediatric dentistry skills. This study aimed to compare dental undergraduates' self-reported experience and confidence in paediatric dentistry within three UK dental schools (Liverpool, Manchester and Sheffield). In April/May 2009, 147 final year dental students completed an anonymous questionnaire which captured their experience of seven core clinical skills in both hospital and outreach settings. A visual analogue scale was also employed to record perceived levels of confidence for six generic activities including: examination, diagnosis and treatment planning; patient selection for treatment under general anaesthesia; operative dentistry; preventive dentistry; management of dento-alveolar trauma, and provision of routine care for children on qualification. The key finding was that Liverpool, Manchester and Sheffield dental students received comparable clinical experiences in paediatric dentistry, which appeared to satisfy the requirements of the General Dental Council's The first five years. One hundred percent had carried out fissure sealants and restorations, and 87-98\% had experience of extractions. Outreach placements were crucial in ensuring students had sufficient opportunity to undertake core skills, notably extractions and pulp therapies. All students reported a lack of confidence in dental trauma management which warrants greater emphasis in the undergraduate curriculum.

\section{INTRODUCTION}

The undergraduate dental curriculum in the UK is guided by the requirements set out in the General Dental Council's (GDC) document The first five years.' The GDC has identified three levels of expertise for the new dental graduate. Firstly, they should be competent at a procedure, defined as 'having sound theoretical knowledge and understanding with adequate clinical experience to resolve clinical problems without assistance'. Alternatively, they should have knowledge of a procedure, defined as ' $h a v$ ing sound theoretical knowledge but with limited clinical or practical experience' And finally they should be familiar with a procedure, defined as 'having a basic

\footnotetext{
1*2,20partment of Oral Health and Development, School of Clinical Dentistry, Claremont Crescent, Sheffield, S10 2TA; ${ }^{3}$ School of Dentistry, University of Liverpool, Pembroke Place, Liverpool, L3 5PS; ${ }^{4}$ School of Dentistry, University of Manchester, Higher Cambridge Street, Manchester, M15 6FH

${ }^{*}$ Correspondence to: Professor Helen Rodd Email: h.d.rodd@sheffield.ac.uk
}

\section{Refereed Paper}

Accepted 1 February 2010

DOI: $10.1038 /$ sj.bdj.2010.207

${ }^{\oplus}$ British Dental Journal 2010; 208: 221-225 understanding of the subject but without having had direct clinical experience'. Although the GDC has stipulated which areas should be covered in the undergraduate curriculum, it respects the diversity of delivery of dental education. Thus local differences between schools such as the oral health needs of their patient population, service structures, research interests, learning and teaching styles are acknowledged.

Dental schools face immense challenges in delivering a satisfactory curriculum to increasing student numbers with everdepleting resources. One of the greatest difficulties is the provision of sufficient patient numbers, and appropriate casemix, to ensure that students have the opportunity to achieve expected clinical competencies. One specialty that has been forthcoming in highlighting changes in undergraduate clinical experience over the past couple of decades is paediatric dentistry. A number of studies have reported significant reductions in the number of restorative procedures being carried out by students in hospital paediatric dentistry clinics. ${ }^{2-4}$ However, reductions in restorations (notably amalgam) and primary molar pulp therapies have generally been matched by increased experience in preventive regimens such as fissure sealants and fluoride therapies. ${ }^{2-4}$ To some extent, these changes have simply reflected reducing caries experience among children ${ }^{5}$ as well as development of new clinical guidelines and policies for evidence-based practice. ${ }^{6-8}$ Nonetheless, potential deficiencies in undergraduate paediatric dentistry experience have been acknowledged, both in the UK and worldwide., ${ }^{3,9}$

In order to address shortfalls in undergraduate experience, increasing emphasis has been placed on the contribution of outreach training. Hunter et al. ${ }^{10}$ conducted a pilot study to determine the impact of a community dental service outreach programme on the self-reported confidence of their dental students in the management of children. Following a 15-day placement, students were found to more confident across a wide range of paediatric dentistry skills, notably in relation to primary molar pulp therapy and extractions. Confidence 
in providing oral health care for patients is considered to be an important educational outcome. ${ }^{11}$ There is now an overwhelming body of evidence to support the educational value of student placements in primary care settings outside the 'traditional' settings of dental schools. ${ }^{12,13}$ Randomised controlled trials, conducted in Sheffield, revealed that outreach training significantly improved students' ability in treatment planning and perceived clinical confidence. ${ }^{14,15}$

The aim of this study was to investigate dental undergraduates' self-reported experience and perceived clinical confidence in paediatric dentistry within three UK dental schools (Liverpool, Manchester and Sheffield). To date, previous reports have been largely limited to single teaching institutes with a paucity of directly comparable data between schools. In view of the diversity of clinical opportunities and learning environments provided by different schools, it was felt that this multi-centred study would offer a more comprehensive insight into the range of paediatric dentistry experience gained by current British graduates.

\section{MATERIALS AND METHODS}

The intended sample was all final year dental students at Liverpool ( $\mathrm{n}=70$ ), Manchester $(n=85)$ and Sheffield $(n=63)$ dental schools.

\section{Data collection}

A two-sided data collection form was designed to include the key clinical procedures, as proposed by the GDC (2008), ${ }^{1}$ which were considered relevant to undergraduate paediatric dentistry. These comprised seven treatment items: fissure sealants; intra-coronal restorations; incisal tip restorations; preformed metal crowns (PMC); primary molar pulp therapy; any trauma-related treatment; and extractions under local anaesthetic. The self-completed anonymous form recorded students' clinical exposure to these treatment items, as a yes/no response, for both outreach and hospital settings. Self-assessed confidence was also recorded in relation to six generic activities including: examination, diagnosis and treatment planning; selection of patients for treatment under general anaesthesia (GA); operative dentistry; preventive dentistry; management of dento-alveolar

Table 1 Percentage of students with self-reported experience in core paediatric dentistry skills within different clinical settings

\begin{tabular}{|c|c|c|c|}
\hline $\begin{array}{l}\text { Procedure } \\
\text { Clinical setting }\end{array}$ & $\begin{array}{l}\text { Liverpool students } \\
(n=40)\end{array}$ & $\begin{array}{l}\text { Manchester students } \\
(\mathrm{n}=49)\end{array}$ & $\begin{array}{l}\text { Sheffield students } \\
(n=58)\end{array}$ \\
\hline $\begin{array}{l}\text { Fissure sealant } \\
\text { Hospital } \\
\text { Outreach } \\
\text { Either setting }\end{array}$ & $\begin{array}{l}88 \% \\
93 \% \\
100 \%\end{array}$ & $\begin{array}{l}53 \% \\
100 \% \\
100 \%\end{array}$ & $\begin{array}{l}100 \% \\
100 \% \\
100 \%\end{array}$ \\
\hline $\begin{array}{l}\text { Restoration } \\
\text { Hospital } \\
\text { Outreach } \\
\text { Either setting }\end{array}$ & $\begin{array}{l}98 \% \\
98 \% \\
100 \%\end{array}$ & $\begin{array}{l}44 \% \\
100 \% \\
100 \%\end{array}$ & $\begin{array}{l}98 \% \\
100 \% \\
100 \%\end{array}$ \\
\hline $\begin{array}{l}\text { Incisal tip restoration } \\
\text { Hospital } \\
\text { Outreach } \\
\text { Either setting }\end{array}$ & $\begin{array}{l}70 \% \\
66 \% \\
83 \% \\
\end{array}$ & $\begin{array}{l}36 \% \\
75 \% \\
78 \% \\
\end{array}$ & $\begin{array}{l}76 \% \\
91 \% \\
97 \% \%^{\mathrm{M}} \\
\end{array}$ \\
\hline $\begin{array}{l}\text { Preformed metal crown } \\
\text { Hospital } \\
\text { Outreach } \\
\text { Either setting }\end{array}$ & $\begin{array}{l}3 \% \\
5 \% \\
8 \%\end{array}$ & $\begin{array}{l}4 \% \\
44 \% \\
43 \% \%^{\mathrm{L}}\end{array}$ & $\begin{array}{l}50 \% \\
20 \% \\
63 \% \%^{\mathrm{L}}\end{array}$ \\
\hline $\begin{array}{l}\text { Pulp therapy primary molar } \\
\text { Hospital } \\
\text { Outreach } \\
\text { Either setting }\end{array}$ & $\begin{array}{l}25 \% \\
18 \% \\
38 \% \\
\end{array}$ & $\begin{array}{l}23 \% \\
82 \% \\
86 \%{ }^{\llcorner}\end{array}$ & $\begin{array}{l}14 \% \\
61 \% \\
64 \% \%^{L}\end{array}$ \\
\hline $\begin{array}{l}\text { Trauma-related treatment } \\
\text { Hospital } \\
\text { Outreach } \\
\text { Either setting }\end{array}$ & $\begin{array}{l}53 \% \\
33 \% \\
63 \%\end{array}$ & $\begin{array}{l}26 \% \\
46 \% \\
50 \%\end{array}$ & $\begin{array}{l}58 \% \\
47 \% \\
74 \%{ }^{\mathrm{M}}\end{array}$ \\
\hline $\begin{array}{l}\text { Extraction under } \\
\text { local anaesthetic } \\
\text { Hospital } \\
\text { Outreach } \\
\text { Either setting }\end{array}$ & $\begin{array}{l}90 \% \\
56 \% \\
87 \%\end{array}$ & $\begin{array}{l}40 \% \\
98 \% \\
98 \%\end{array}$ & $\begin{array}{l}67 \% \\
91 \% \\
95 \%\end{array}$ \\
\hline
\end{tabular}

trauma, and provision of routine care for children on qualification. A visual analogue scale was used to measure reported confidence. Students were asked to place a mark on a $10 \mathrm{~cm}$ line where $0.0 \mathrm{~cm}$ represented 'no confidence at all', and $10 \mathrm{~cm}$ represented 'complete confidence'. One investigator then measured these distances in centimetres using a $10 \mathrm{~cm}$ ruler.

Questionnaires were distributed to final year dental students at the three centres in April/May, 2009, a few weeks before their final examinations. A statement was sought from each of the three paediatric dentistry departments to clarify the amount of clinical time their students spent treating children in either hospital and/or outreach settings.

\section{Data analysis}

Data were recorded using the statistical package for social sciences (SPSS v14). A chi-squared test was used to compare the proportion of students that had experience of each of the seven core competencies in the three schools. Preliminary analysis of VAS data for confidence levels showed that it was normally distributed, thus a one-way analysis of variance (ANOVA), followed by a Tukey test, were used to determine statistically significant differences in means. Significance levels were set at $\mathrm{p}<0.05$.

\section{RESULTS}

\section{Participants}

A total of 147 final year dental students participated in the survey across the three dental schools as follows: Liverpool, $\mathrm{n}=40$ (57\% response); Manchester, $\mathrm{n}=49$ (58\% response) and Sheffield, $\mathrm{n}=58$ (89\% response). There was a similar proportion of male (48\%) and female (52\%) respondents. Preliminary statistical analysis revealed no differences in responses according to gender, thus the data were pooled for male and female students.

\section{Clinical teaching}

There were marked differences between the three schools in the proportion of time that students spent treating children in hospital and primary care clinics. Liverpool students 
started their hospital clinical rotation in paediatric dentistry in their 3rd year. They had a fortnightly rotation in the paediatric dentistry clinic where they started seeing children, mainly for prevention and simple restorative work. In their 4th year, students arranged their own appointments to treat paediatric patients allocated to them: on average each student saw two patients over multiple treatment visits. In addition, students underwent a ten-week outreach attachment where they treated children in a variety of primary care settings for one day a week. In their 5th year, students returned to the hospital paediatric dentistry clinic to continue to see their own booked patients and undergo a one-week rotation involving casualty, new patients and trauma clinics. In contrast, Manchester students predominantly gained experience of clinical paediatric dentistry in outreach. They started treating children in their 4th year in a variety of outreach clinics for one session each week. This continued in their 5 th year, for one day a week for 12 weeks. In year 5, students also rotated through new patient clinics, GA assessment clinics, and inhalation sedation clinics in the dental hospital. Sheffield students started seeing paediatric dentistry patients in their 4 th year, in a two-week block, before a 20-week outreach placement. They returned to the dental hospital in their 5th year and commenced fortnightly paediatric dentistry treatment clinics. In addition, they attended a minimum of three paediatric dentistry new patient clinics.

\section{Experience of clinical skills}

Table 1 shows the percentage of students, from each school, who had reportedly undertaken the seven key clinical skills in the hospital, outreach or at least one of these clinical settings. All students, in each of the three dental schools had gained experience in placing fissure sealants and restorations for a child patient. The majority of students had also had opportunity to carry out extractions (range $=87 \%-98 \%$ ) and place an incisal tip restoration (range $=78 \%-97 \%$ ). However, experience in placing a PMC, carrying out primary molar pulp therapy or management of dento-alveolar trauma was considerably more limited. Liverpool graduates had a particularly low exposure to PMCs (8\%) and pulp therapy in primary teeth $(38 \%)$.

Table 2 Mean visual analogue scores (VAS) for self-reported confidence of students in core areas of paediatric dentistry-related activity

\begin{tabular}{|c|c|c|c|}
\hline \multirow[b]{2}{*}{ Activity } & \multicolumn{3}{|l|}{ Mean VAS (SD) } \\
\hline & $\begin{array}{l}\text { Liverpool students } \\
(\mathrm{n}=40)\end{array}$ & $\begin{array}{l}\text { Manchester students } \\
(n=49)\end{array}$ & $\begin{array}{l}\text { Sheffield students } \\
(n=58)\end{array}$ \\
\hline $\begin{array}{l}\text { Examination, diagnosis } \\
\text { and treatment planning }\end{array}$ & $6.3(1.47)$ & $6.7(1.21)$ & $6.8(1.05)$ \\
\hline Restorative procedures & $6.0(1.52)$ & $6.6(1.22)$ & $6.7(1.30)^{\mathrm{L}}$ \\
\hline $\begin{array}{l}\text { Selection of patients for } \\
\text { GA, risks and instructions }\end{array}$ & $5.4(1.70)$ & $4.8(1.78)$ & $6.3(1.78)^{\mathrm{M}}$ \\
\hline $\begin{array}{l}\text { Preventive treatments } \\
\text { (FS, diet advice, } F \text {, oral } \\
\text { hygiene instruction) }\end{array}$ & $7.7(1.51)$ & $8.1(1.26)$ & $8.6(1.00)^{\llcorner}$ \\
\hline $\begin{array}{l}\text { Management of } \\
\text { dental trauma }\end{array}$ & $4.4(2.14)$ & $5.1(2.07)$ & $5.4(1.89)^{L}$ \\
\hline $\begin{array}{l}\text { Provision of routine care } \\
\text { within general dental practice }\end{array}$ & $6.9(1.53)$ & $7.2(1.41)$ & $7.4(1.52)$ \\
\hline
\end{tabular}

There were relatively few significant differences in the percentage of students that had experienced these clinical modalities between the three student groups. However, significantly more Sheffield students had carried out an incisal tip restoration and undertaken trauma-related treatments than Manchester students, and significantly more Sheffield and Manchester students had experience of a PMC or pulp therapy than Liverpool students ( $p<0.05$, chi-squared test).

In general, students were more likely to have undertaken procedures in outreach settings rather than in hospital paediatric dentistry clinics. However, there were two marked exceptions: Sheffield students were much more likely to have carried out a PMC in the hospital environment (50\%) versus outreach (20\%) and a greater proportion of Liverpool students had performed an extraction in the dental hospital (90\%) than at an outreach clinic (56\%).

\section{Self-reported confidence}

In general, students considered themselves to have above average confidence (VAS $\geq 5.0$ ) in most of the generic activities, with the exception of patient selection and information-giving before a dental GA (Manchester students; mean VAS $=4.8$ ) and management of paediatric dental trauma (Liverpool students; mean VAS $=4.4$ ) (Table 2). Students rated themselves as being most confident in preventive treatments, such as fissure sealants, oral hygiene instruction, dietary advice and fluoride prescription (mean VAS range $=7.7-8.6$ ). They also perceived themselves as being well prepared to provide routine care for children in general dental practice on qualification (mean VAS range $=6.9-7.4$ ). In terms of interschool differences, Sheffield students rated themselves as significantly more confident than Liverpool students in carrying out restorative and preventive treatments and managing dento-alveolar trauma ( $\mathrm{p}<0.05$, ANOVA). They also reported themselves as significantly more confident than Manchester students in the selection and preparation of patients for a dental GA.

\section{DISCUSSION}

\section{Meeting educational outcomes}

The results of this preliminary survey showed that the majority of students had gained clinical experience in fissure sealant application, restoration and extraction of teeth in paediatric patients. These are clinical skills which the GDC stipulates students must be competent at, thus it was reassuring that these learning opportunities were widely offered. However, the investigators did not seek data from each school as to how competency in these procedures was actually determined, and whether any numerical targets were required for these clinical skills. Another required competency is that of incisal restorations, although it is not a procedure restricted to paediatric dentistry. This study found that between 83 and 97\% of students 
had specific experience of this type of restoration in children, thus combined with their adult restorative experience, it is likely that this learning outcome was universally achieved.

Students in all three centres reported lower levels of exposure to the provision of PMCs, pulp therapy of primary teeth and management of dento-alveolar trauma. According to the The first five years, students are only expected to have knowledge of these procedures, ${ }^{1}$ and thus need only have limited clinical experience. The findings from this study compare favourably with those of previous studies conducted in other dental schools. ${ }^{3,4}$ Data from Dublin dental school revealed that 71\% of 2002 graduates had experience of primary molar pulp therapy and 68\% has placed a PMC. ${ }^{4}$ Only 8\% of students graduating in 2001 from Guy's, King's and St Thomas' dental institute had experience of placing a PMC and $47 \%$ had carried out a primary molar pulpotomy. ${ }^{3}$ Interestingly, 1994 graduates from Sheffield dental school had such little experience of PMCs, the data were not reported and less than $1 \%$ had experience of primary molar pulp therapy. ${ }^{2}$

\section{Inter-school comparisons}

The first thing to highlight is the spirit of openness demonstrated by the three dental schools. In a culture of increasing competition between universities, largely driven by external assessment of teaching and research quality, it is encouraging that the participating schools were prepared to share and publicise their students' experiences of paediatric dentistry. Interestingly, despite the diversity of clinical timetabling and relative proportion of time spent in hospital and/or outreach settings, there were surprisingly few differences between the student groups. The main exception was the low level of PMC experience gained by Liverpool students. Although this is not a required GDC competency, paediatric dentists view PMCs as a fundamental treatment procedure. Thus Liverpool is considering strategies to increase student opportunities for undertaking this procedure. Sheffield now widely teaches the use of the 'Hall technique' for the placement of PMCs which may explain why a greater proportion of their students had experience of this clinical skill. The technique is considerably less demanding than the conventional approach and thus offers an invaluable restorative option for more junior dental students. ${ }^{16,17}$

Another interesting finding arising from this study was that in the two centres with a significant outreach component (Manchester and Sheffield), students were more likely to have carried out primary molar pulp therapy and extractions in outreach clinics than during hospital sessions. This may be explained by the difference in case-mix presenting to primary care and tertiary services. In the main, paediatric dentistry referrals to dental hospitals include anxious or medically compromised children with very high caries rates. These children often require treatment by staff and the use of inhalation sedation or even GA. Thus opportunities for students to carry out pulp therapies or single tooth extractions are more limited. In contrast, primary care services tend to see more regularly attending and cooperative children who are more likely to meet the criteria for primary molar pulp therapy or extractions under local anaesthetic. In keeping with previous reports, this study clearly demonstrates the invaluable and increasing role that outreach teaching plays in meeting learning outcomes for dental students. ${ }^{10,15,18,19}$

\section{Confidence in relation to trauma management}

The one area in which dental students universally reported low levels of confidence was the management of dental trauma. This finding would appear to be corroborated by a number of previous studies which all have highlighted the lack of confidence and competence in trauma management among UK dentists. ${ }^{20-22}$ Indeed these previous papers have all called for an increase in trauma-related teaching within undergraduate and postgraduate dental curricula. The implications of poor trauma management are considerable with far-reaching economic, psychosocial and oral health consequences for the patient. It is therefore of paramount importance that dental students are equipped with the knowledge and skills to provide appropriate emergency trauma management for their future patients. This poses a considerable challenge for teachers, as acute dental trauma cannot be predicted to allow equitable exposure for all students. Innovative learning methods, other than direct clinical contact, therefore have to be explored such as: role play; interactive electronic programmes; video demonstrations; case-conferences, and laboratory-based skills. As a direct result of this study, the investigators have pooled their resources and developed seven trauma case scenarios which will, in future, be used for small group teaching with all final year students. The value of this intervention will then be measured. In addition, it is hoped that students may be more widely timetabled to attend consultant-led paediatric dentistry trauma clinics within the respective hospitals.

\section{Study design}

This study sought self-reported data from students about their clinical experience thus the validity of the data may be open to question. However, the priority was for anonymity rather than attempting to corroborate results with students' clinical record books. Furthermore, as this was primarily a comparative study, any inaccuracies in reported clinical experience would be expected across the three groups and would still allow for a meaningful comparison.

\section{CONCLUSION}

This study found that Liverpool, Manchester and Sheffield dental students received comparable clinical experiences in paediatric dentistry, which appeared to satisfy the requirements of the GDC's The first five years. ${ }^{1}$ Outreach placements were seen to be crucial in ensuring that students had sufficient opportunity to undertake core clinical skills for children. Students universally reported a lack of confidence in dental trauma management and this is the one area that the investigators will now be targeting for enhanced student learning.

1. General Dental Council. The first five years: a framework for undergraduate dental education. 3rd ed. London: GDC, 2008.

2. Rodd H D. Change in undergraduate experience in clinical pediatric dentistry. J Dent Educ 1994; 58: 367-369.

3. Seddon R D. Undergraduate experience of clinical procedures in paediatric dentistry in a UK dental school during 1997-2001. Eur J Dent Educ 2004; 8: $172-176$.

4. Finucane D, Nunn J H, O'Connell A C. Paediatric dentistry experience of the first cohort of students to graduate from Dublin Dental School and Hospital under the new curriculum. Int J Paediatr Dent 2004; 14: 402-408.

5. Pitts N B, Boyles J, Nugent Z J, Thomas N, Pine C M The dental caries experience of 5 -year-old children in Great Britain (2005/6). Surveys coordinated by 
the British Association for the study of community dentistry. Community Dent Health 2007; 24: 59-63.

6. Fayle S A, Welbury R R, Roberts J F. British Society of Paediatric Dentistry: a policy document on management of caries in the primary dentition. Int J Paediatr Dent 2001; 11: 153-157.

7. Rodd H D, Waterhouse P J, Fuks A B, Fayle S A, Moffat M A; British Society of Paediatric Dentistry. Pulp therapy for primary molars. Int J Paediatr Dent 2006; 16(Suppl 1): 15-23.

8. Kindelan S A, Day P, Nichol R, Willmott N, Fayle SA. UK National Clinical Guidelines in Paediatric Dentistry: stainless steel preformed crowns for primary molars. Int J Paediatr Dent 2008; 18(Suppl 1): 20-28.

9. Lekic P C, Sanche N, Odlum O, deVries J, Wiltshire W A. Increasing general dentists' provision of care to child patients through changes in the undergraduate pediatric dentistry program. J Dent Educ 2005; 69: 371-377.

10. Hunter $M L$, Oliver $R$, Lewis $R$. The effect of community dental service outreach programme on the confidence of undergraduate students to treat children: a pilot study. Eur J Dent Educ 2007;

11: 10-13.
11. Stewart J, O'Halloran C, Barton J R et al. Clarifying the concepts of confidence and competence to produce appropriate self-evaluation measurement scales. Med Educ 2000; 34: 903-909.

12. Elkind A. Outreach teaching: is this the future for dental education? Br Dent J 2002; 193: 111-112.

13. Lennon M A, Ireland R S, Tappin J et al. The personal dental service as a setting for an undergraduate clinical programme. Br Dent J 2004; 196: 419-422.

14. Smith $M$, Lennon M A, Brook A H, Ritucci L, Robinson P G. Student perspectives on their recent dental outreach placement experiences. Eur J Dent Educ 2006; 10: 80-86.

15. Smith $M$, Lennon M A, Brook A H et al. A randomised controlled trial of the effect of outreach placement on treatment planning by dental students. Br Dent J 2006; 201(Suppl): 27-31.

16. Innes N P, Stirrups D R, Evans D J, Hall N, Leggate $M$. A novel technique using preformed metal crowns for managing carious primary molars in general practice - a retrospective analysis. Br Dent J 2006; 200: 451-454.

17. Innes N P, Evans D J, Stirrups D R. The Hall technique is an effective treatment option for carious primary molar teeth. Evid Based Dent 2007; 9: 44-45.

18. Elkind $A, B$ linkhorn A S, Blinkhorn F A, Duxbury J T, Hull PS, Brunton P A. Developing dental education in primary care: the student perspective. Br Dent J 2005: 198: 233-237.

19. Craddock H L. Outreach teaching - the Leeds experience: reflections after one year. Br Dent J 2008; 204: 319-324.

20. Hamilton FA, Hill F J, Holloway P J. An investigation of dento-alveolar trauma and its treatment in an adolescent population. Part 2. Dentists' knowledge of management methods and their perceptions of barriers to providing care. Br Dent J 1997; 182: 129-133.

21. Maguire A, Murray J J, Al-Majed I. A retrospective study of treatment provided in the primary and secondary care services for children attending a dental hospital following complicated crown fracture in the permanent dentition. Int J Paediatr Dent 2000; 10: 182-190.

22. Kostopoulou M N, Duggal M S. A study into dentists' knowledge of the treatment of traumatic injuries to young permanent incisors. Int J Paediatr Dent 2005; 15: 10-19. 